\title{
Post-Natal Gestational Age Assessment Using Sonographic Measurement of Femoral Length
}

\author{
Anupama Deka', Manoj $\mathrm{GM}^{2}$, Prabhu $\mathrm{BJ}^{3}$
}

${ }^{1}$ Dr. Anupama Deka, MBBS, MD, Professor and HOD, Department of Paediatrics, ${ }^{2} \mathrm{Dr}$. Manoj GM, MBBS, MD post graduate student, Department of Paediatrics, ${ }^{3} \mathrm{Dr}$. Prabhu BJ, MBBS, MD post graduate student, Department of Radiology. All from the Silchar Medical College, Silchar, Assam, India.

\section{Address for correspondence:}

Dr. Anupama Deka (Professor and Head)

Department of Paediatrics

Silchar Medical College

Silchar, Assam, India

E-mail: Anupamadeka100@gmail.com

Acknowledgements: None

Funding: Nil

Conflict of Interest: None

Permission from IRB: Yes

Ethical dilemmas faced during study: No

\section{How to cite}

Anupama Deka, Manoj GM, Prabhu BJ. PostNatal Gestational Age Assessment Using Sonographic Measurement of Femoral Length. J Nepal Paediatr Soc 2016;36(3):268-272.

doi: http://dx.doi.org/10.3126/jnps.v36i3.15153

This work is licensed under a Creative Commons Attribution 3.0 License.

\section{(c) (i)}

Key words: Gestational age, Neonatal ultrasosnography, Femoral length, New Ballard score.

\section{Introduction}

Cestational age (GA) has emerged as the single most important 3 predictor of mortality and morbidity in neonatal literature ${ }^{1,2,3}$. GA assessment is important for following reasons

1. To decide the method of feeding a newborn(tube/spoon/breast feeding)

2. To decide level of care for a newborn (level 1/2/3)

3. Therapeutic hypothermia is used only after 36 weeks GA. Contraindicated below 36 weeks of GA. 
4. Prophylactic surfactant is considered in less than 32 weeks of $\mathrm{GA}$.

5. These days late preterm $34(0 / 7)$ to $36(6 / 7)$ are gaining importance because of complication associated with them.

These are the few examples out of so many reasons to know accurate $\mathrm{GA}^{5}$. An accurate GA is a better predictor of neonatal outcome than birth weight ${ }^{4}$. The methods available for GA estimations antenatally are based on last menstrual age (LMP), antenatal ultrasound and postnatally new Ballard score.

Problems with the accuracy of gestational age computed by LMP on birth certificates have been documented ${ }^{6,7,8,9,10}$. Inaccuracy of LMP-based gestational age can be caused by biologically associated errors in menstrual cycles and by human error in recall or data entry ${ }^{11,12}$. Inherent in estimating gestational age with LMP is the assumption that all women have a regular 28-day menstrual cycle and ovulate 14 days after the first day of their LMP. However, because timing of ovulation varies, even with accurate recall and data entry of the LMP, estimates of gestational age based on LMP can be inaccurate. For example, one study found that $10 \%$ of women had cycles $<25$ days long, $12 \%$ were between 31 and 35 days, and $3 \%$ were 36 days or longer, while $5 \%$ were too irregular to say ${ }^{13}$.

Early trimester ultrasound has been established clinically as the gold standard ${ }^{14}$ but only $52 \%$ will have three antenatal visits and most of the women seek medical care $1^{\text {st }}$ time at the time of delivery in which case GA estimation by any method is not possible ${ }^{15}$.

After birth, clinical methods are used to assess GA. These use the difference in physical and neurological maturation at different GA. The Dubowitz scoring system is an excellent estimate of GA in newborn infant older than 34 weeks but is unsuitable, by the nature of its design, for the low birth weight neonates ${ }^{16,17,18}$. The Ballard score system, using principles similar to those of Dubowitz, is less complex and less time consuming and has been validated for use in premature newborns ${ }^{16,18,19}$. Further modification to Ballard score has made it suitable for use in extremely premature neonates ${ }^{20}$. Clinical methods, however, remain subjective and can result in a substantial error in the assessment of GA, especially of low birth weight babies and babies with perinatal asphyxia with hypoxic ischemic encephalopathy.

Assessment of gestational age in the second trimester by real-time ultrasound measurement of the femur length, adds a new parameter for estimating fetal age by ultrasound which would appear to be as accurate as that of biparietal diameter ${ }^{21}$. Using similar principles we hypothesized that biometry of long bones with sonography imaging is feasible after birth and may be used to assess GA. The calculated validity in predicting menstrual age from fetal femoral length is \pm 9.5 days between 12 and 23 weeks of GA \pm 22 days between 23 to 40 weeks of GA. We have devised a method of measuring femoral length (FL) postnatally with ultrasonography. This may permit estimation of GA using tables of fetal FL measurements.

\section{Material and Methods}

Study conducted in neonatal intensive care unit, Silchar Medical College, Silchar, Assam, India. Ninety neonates from 32 weeks to 40 weeks of gestational age (GA), 10 from each GA, born to mother with regular menstrual period and accurate recall of LMP were included in the study. Neonates with; IUGR, Any life threatening congenital conditions, Cardio respiratory instability, GA less the 32 weeks and more than 40 weeks, Age more the 1 week old, Microcephaly or macrocephaly, Congenital Bony deformities and Neonates with facial dysmorphism were excluded from study. The protocol was approved from ethical committee of Silchar Medical College, Silchar and consent of respective parents taken before enrolling neonates in the study.GA (number of completed weeks) was calculated for each neonates from accurate LMP. The modified new-Ballard scoring system was used to reconfirm GA in all newborn infants.

The femur was imaged sonographyically by trained radiologist with $4 \mathrm{MHz}$ curvilinear transducer aligned longitudinally along the thigh. Sterile gloves containing $300 \mathrm{ml}$ distil water facilitated imaging. FL was measured by electronic calipers after clear visualization of the ends of the femoral shaft (two ends of diaphysis were taken, ephiphyses not included) as shown in Fig 1.

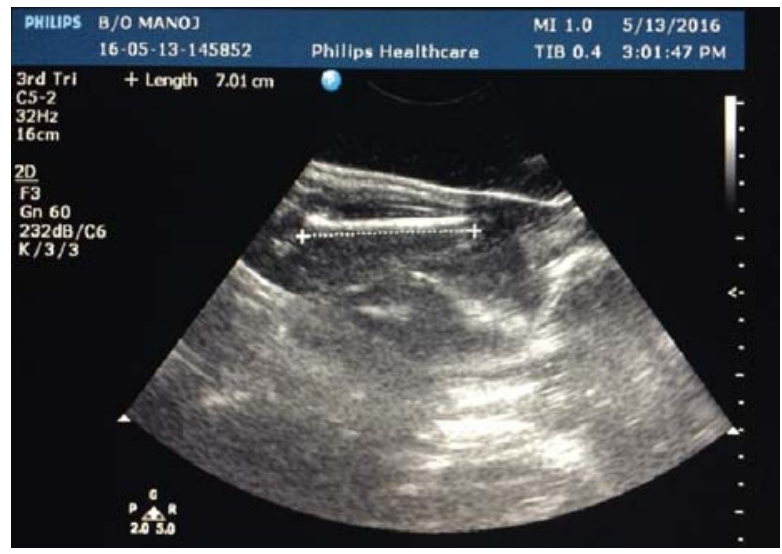

Fig 1: Showing method of sonographic measurement of femoral length. 
Statistical analysis was performed using the GA calculated from LMP as the "gold standard". Student $t$-test was used to analyze residuals.

\section{Results}

All the newborn had weight, length and head circumference appropriate for GA as calculated from LMP. Birth weights were compared with standard reference to exclude IUGR neonates as shown in Table 1.

Table 1. Average birth weight of neonates in each GA

\begin{tabular}{|c|c|}
\hline GA (LMP) ${ }^{*}$ in weeks & Birth wt*** in $\mathrm{Kg}$ \\
\hline 32 & $1.72 \pm 0.5$ \\
\hline 33 & $1.95 \pm 0.6$ \\
\hline 34 & $2.13 \pm 0.4$ \\
\hline 35 & $2.32 \pm 1.2$ \\
\hline 36 & $2.42 \pm 0.9$ \\
\hline 37 & $2.68 \pm 1.3$ \\
\hline 38 & $2.87 \pm 0.8$ \\
\hline 39 & $3.03 \pm 1.6$ \\
\hline 40 & $3.14 \pm 1.0$ \\
\hline
\end{tabular}

*** Birth weight are between $50^{\text {th }}$ and $10^{\text {th }}$ percentile as per AAP intrauterine growth chart.
Gestational age estimated by new-Ballard score over estimated GA in comparison with GA calculated from LMP as shown in Table 2. And the difference is significant as $p$ value is $<0.05$.

Femoral length measured was compared with fetal standard femoral length. A progressive increase in FL measurement was noted with increasing GA, similar to that seen in fetal FL measurements. Comparison between the measured neonatal FL and the predicted FL revealed no statistical significance $(p=>0.05)$ as shown in Table 3.

\section{Discussion}

Rapid advances in neonatal intensive care have demanded critical analyses of neonatal mortality and morbidity ${ }^{16}$. GA is recognized as an important predictor of neonatal mortality and morbidity ${ }^{22,23}$. Antenatal GA assessment relies heavily on accurate menstrual history with regular cycle. These are often unavailable in pregnancies, and studies have shown that GA assessment by LMP is unreliable in 25 to $59 \%$ of pregnancies. This is especially true in pregnancy complicated by premature labor, post maturity, as poor antenatal care and teenage mother are common

Table 2: Comparison of GA calculated from accurate LMP* and New Ballard score.

\begin{tabular}{ccc}
\hline GA(LMP) ${ }^{*}$ in weeks & GA by Ballard score (wk) & p-value \\
\hline 32 & $33.4 \pm 0.8$ & \\
33 & $34.2 \pm 1.2$ & \\
\hline 34 & $36.3 \pm 0.6$ & \\
\hline 35 & $38.1 \pm 1.4$ & 0.0007 \\
\hline 36 & $37.0 \pm 1.2$ & \\
\hline 38 & $38.2 \pm 1.0$ & \\
\hline 39 & $38.0 \pm 0.8$ & \\
\hline 40 & $41.2 \pm 1.2$ & \\
\hline
\end{tabular}

Table 3: Comparison of average measured neonatal femoral length with fetal standard FL in each GA

\begin{tabular}{cccc}
\hline \multirow{2}{*}{ GA(LMP) ${ }^{*}$ in weeks } & \multicolumn{2}{c}{ Femoral Length(mm) } & \multirow{2}{*}{$\boldsymbol{p}$-value } \\
\cline { 2 - 3 } 32 & Neonatal & Foetal $^{\text {*** }}$ & 61.2 \\
\hline 33 & $60.7 \pm 2.3$ & 63.1 & \\
\hline 34 & $64.9 \pm 1.8$ & 64.9 & \multirow{3}{*}{$p$-value $=0.375$} \\
\hline 35 & $65.6 \pm 3.2$ & 66.6 & \\
\hline 36 & $67.3 \pm 1.4$ & 68.2 & \\
\hline 38 & $69.4 \pm 2.6$ & 69.7 & \\
\hline 39 & $70.2 \pm 1.9$ & 71.1 & \\
\hline 40 & $71.0 \pm 3.1$ & 72.4 & \\
\hline
\end{tabular}

*** Predicted fetal value from Rumack USG: text book of radiology. 
association $^{24}$. Sonographic assessment of GA is extremely useful for pregnancies less the 18 weeks of GA but the variability of data increases as pregnancy progresse ${ }^{25}$, furthermore, this narrow window of time limits its application.

Postnatal assessment of GA (New Ballard score and Debowitz score) uses clinical development criteria at various stages of gestation and correlates stages of physical and neurological development to $\mathrm{GA}^{3,26}$. All scoring systems involve subjectivity and clinical acumen. The physiologic criteria can often be affected by generalized edema that commonly occurs in sick premature newborn and neurologic criteria can be altered by perinatal asphyxia, any condition leading to CNS depression ${ }^{25}$. The Ballard maturational scoring system has been useful in GA of extremely premature newborns. However it tends to overestimate GA as much as 2 to 3 weeks ${ }^{16,18}$. Further clinical methods are time consuming, require experience, and necessitate the handling of sick newborns. These methods can't be used for paralyzed infants and generally done by junior staff in the NICU, further decreasing their accuracy.

Considering all these above facts we framed a cross sectional study in which we selected 90 healthy neonates from 32 to 40 weeks of GA, 10 from each GA. Mackanjee et $\mathrm{al}^{27}$ did similar study by taking preterm neonates from 23 to 33 weeks of GA. Table 1 explains average weight of neonates in each GA. This was compared with AAP intrauterine growth charts to rule out IUGR neonates from study.

As seen from table 2 that, in most of the cases New Ballard over estimated the GA. Similar finding was seen in Mackanjee et $\mathrm{al}^{27}$. In Table 3 we have calculated average $F L$ of neonates from each $G A$, and it was seen that with increasing GA femoral length also increases. Similar finding of, increasing FL with increasing GA was seen in study conducted by Mackanjee et al. We compared our result with fetal standard femoral length

\section{References}

1. Malan AF, Higgs SC: Gestational age assessment in infants of in infants of very low birth weight. Arch Dis Child 1975;50-322.

2. Wood B, Katz V, Bose C, survival morbidity of extremely premature infants based on obstetric assessment of gestational age. Obstetgynecol 1989;74:889.

3. Gagliardi L, Simone F,DelPreteA,et al : Precision of gestational age assessment in the neonate. ActaPaeditr 1992;81:95 taken from Rumack USG: text book of radiology. Many other studies on antenatal femoral length also showed increasing FL with increasing GA.

The lack of "gold standard" for GA estimation makes evaluation difficult. We have used pregnancies with accurate menstrual history as true GA. And it was compared by GA calculated by new Ballard score. Results showed that sonographic FL measurements can be used to estimate GA in newborns who do not have any risk factor that might result in IUGR. Sonographic measurements of FL compare with antenatal values and have advantage of objectivity and can be used in premature, neurologically depressed, sedated and paralyzed infants. The method is also rapid, a single estimation taking less than 3 minutes of contact with the baby. The objectivity and reproducibility of sonographic FL measurements are evident in the high inter-observer and intra-observer reliability data.

\section{Conclusion}

We conclude that GA estimation by $\mathrm{FL}$ measurements is a rapid, objective method of GA assessment in newborns without IUGR. It gives accurate GA in comparison to New Ballard score. We believe that this method of GA assessment may enable GA to be more objective perinatal attribute, and it may improve neonatal diagnosis, treatment modality, outcome and the design of clinical trials in neonatology.

\section{Limitation of Study}

Study has limitation to calculate GA in IUGR neonates as it may show false low GA as IUGR causes shortening of long bones. There is need to be more and large population studies to prove usefulness of femoral length measurement by ultrasonography in estimation of postnatal GA and to validate the values. There is a need to do comparative study of accuracy of estimation of postnatal GA in IUGR neonates by New Ballard score and femoral length measurement by ultrasonography.

4. MLP. Gregory, CR Martin, and JP Cloherty neonatal hyperbilirubinemia. In: Cloherty JP, EC Eichenwald, Hansen AR, Ann R Stark (Eds) Manual of neonatal care. $7^{\text {th }}$ edition Philadelphia: LippincottWillems and Wilkins:2012

5. Msall M E, Buck GM, Rogers B T,et al: Predictors of mortality, morbidity, and disability ina cohort of infants <28weeks gestation. ClinPediatr 1993;32:521.

6. David RJ. The quality and completeness of birthweight and gestational age data in computerized birth files. Am J Pub Health 1980;70:964-973. 
7. Kramer MS, Platt RW, Wen SW, Joseph KS, Allen $A$, Abrahamowicz $M$, et al. A new and improved population-based Canadian reference for birth weight for gestational age. Pediatrics 2001;108:E35.

8. Zhang J, Bowes WA Jr. Birth-weight-for-gestationalage patterns by race, sex, and parity in the United States population. ObstetGynecol 1995;86:200-208.

9. Vahratian A, Buekens P, Bennett TA, Meyer RE, Kogan MD, Yu SM. Preterm delivery rates in North Carolina: are they really declining among non-Hispanic African Americans? Am J Epidemiol 2004;159:59-63.

10. TentoniS,AstolfiP, DePasqualeA, ZontaLA. Birthweight by gestational age in preterm babies according to a Gaussian mixture model. BJOG 2004;111:31-37.

11. Savitz DA, Terry JW Jr, Dole N, Thorp JM Jr, Siega-Riz $\mathrm{AM}$, Herring $\mathrm{AH}$. Comparison of pregnancy dating by last menstrual period, ultrasound scanning, and their combination. Am J ObstetGynecol 2002;187:1660666

12. Waller DK, Spears WD, Gu $Y$, Cunningham GC. Assessing number-specific error in the recall of onset of last menstrual period. Paediatr Perinatal Epidemiol 2000;14:263-67.

13. Rowland AS, Baird DD, Long S, Wegienka G, Harlow SD, Alavanja M, et al. Influence of medical conditions and lifestyle factors on the menstrual cycle. Epidemiology 2002;13:668-74.

14. Dietz, P. M., England, L. J., Callaghan, W. M., Pearl, M., Wier, M. L. and Kharrazi, M. A comparison of LMP-based and ultrasound-based estimates of gestational age using linked California live birth and prenatal screening records. Pediatr Perinatal Epidemiol 2007;21:62-71. doi: 10.1111/j.1365-3016.2007.00862.x

15. Med India network for health: online citation; dated 18.6.16

16. Alexander GR: de Caunes F, Hulsey TC, et al: Validity of postnatal assessment of gestational age :
A comparison of the method of ballard et al, and early ultrasonography. Am J ObstetGynecol 1992; 166:891

17. Spinnato JA: Inaccuracy of Dubowitz gestational age in low birth weight infants. ObstetGynecol 1984;63:491

18. Sanders M, Allen M,Alexander GR, et al: Gestational age assessment in preterm neonates weighing less than 1500 grams. Pediatrics1991;88:542

19. Ballard JL, Novak KK, Driver M: A simplified score for assessment of fetal maturation of newly born infants. $J$ Pediatr 1979;95:769

20. Ballard JL, Khoury JC, Weding K, et al: New Ballard score, expanded to include extremely newborn infants. J Pediatr 1991;119:417

21. John T. Queenan, M.D., Department of Obstetrics and Gynecology, Georgetown University Hospital, 3800 Reservoir Road, N. W., Washington, D. C., 2007.

22. Allen $\mathrm{MC}$, Donohue Pk,Dusman $\mathrm{AE}$ : the limit of viability - neonatal outcome of infants born at 22 to 25 weeks gestation. N Eng J Med 1993;329:1597.

23. Robertson PA, SnidermanSH,Laros RK Jr, Neonatal morbidity according to gestational age and birth weight from tertiary care center in the United States, 1983 through 1986. Am J ObstetGynecol 1992;166:1629.

24. Campbell S, Warsof SL, Little D, et al: Routine ultrasound screening for the prediction of gestational age. ObstetGynacol 1985;65:613.

25. DiPietro J A,Allen MC: Estimation of gestational age: Implications for developmental research. Child Dev 1991;62:1184.

26. Ballard JL, Novak KK, Driver M: A simplified score for assessment of fetal maturation of newly born infants. J Pediatr 1979;95:769.

27. Hasu R Mackanjee, Bogdan M lliescu, William B Dawson; Assessment of postnatal gestational age using sonographic measurements of femoral length. $J$ Ultrasound Med 1996;15:115-20. 